\title{
Total excision of lumps and reconstructed the scrotum wall in situ for multiple epidermal cysts of scrotum: a case report
}

\section{ShangChao Wu}

Shenzhen Sami Medical Center

GuanYi Li

Shenzhen Sami Medical Center

Hui Xu

Shenzhen Sami Medical Center

Wenbin Niu

Shenzhen Sami Medical Center

Xin Zhong

Shenzhen Sami Medical Center

Fang Li ( $\sim$ lifang@ssmc-sz.com )

Shenzhen Sami Medical Center

\section{Case report}

Keywords: Scrotum, Multiple, Epidermal cysts, Histopathologic

Posted Date: May 6th, 2021

DOl: https://doi.org/10.21203/rs.3.rs-413447/v1

License: (9) (i) This work is licensed under a Creative Commons Attribution 4.0 International License. Read Full License 


\section{Abstract}

\section{Background}

Epidermoid cysts are the common benign epithelial cysts that may occur in the dermis or subcutaneous tissue. It have been observed in several organs, especially in the skin of the scalp, ear, face, and back.However, the multiple epidermal cysts over the scrotum is a rare condition. We report a case of total excision of lumps and reconstructed the scrotum wall in situ for multiple epidermal cysts of scrotum.

Case presentation:

A 23-year-old man presented with multiple lumps on the scrotum skin for more than 7 years. On physical examination, multiple lumps were found arising from the scrotal skin, the largest one measuring $1.5 \mathrm{~cm}$. Ultrasonography of the local part indicated testes of normal consistency without free fluid in the tunica of scrotum. The laboratory workup revealed that the blood cell, blood electrolyte and thyroid hormone were within the normal limits.A total excision of scrotal lumps and reconstructed the scrotum wall in situ was performed in this case. And the histopathologic of the specimen is demonstrated an epidermal cysts.

\section{Conclusion}

Multiple epidermal cysts over the scrotum are extremely rare, and correct diagnosis depends on the clinical history, radiological dates,clinical appearance,physical features and histopathologic analysis. The accumulation of further cases is needed to help understand the precisely histogenesis, diagnosis, and treatment of this disease.

\section{Background}

Epidermoid cysts are the common benign epithelial cysts, comprising $85-90 \%$ of all excised cysts [1-2]. It appears as a painless, soft lesion of variable size with intact overlying skin, and may develop anywhere in the body [3]. They present as well-circumscribed firm subcutaneous nodule formed by downgrowth and cystic expansion of the epidermal squamous epithelium. A nodule is filled with keratinous debris and cholesterol or sebaceous materials. In this article, we report a multiple scrotal epidermal cyst of a 23-yearold man with multiple epidermal cysts on the scrotum for more than 7 years,and a total excision of scrotal lumps and reconstructed the scrotum wall in situ was performed in this case..We discuss the diagnosis, evaluation and management of multiple epidermal cysts of scrotum.

\section{Case Presentation}

A 23-year-old man presented to our department with the chief complaints of small multiple slow-growing lumps all over the scrotum without pain since 7 years ago. The medical history of him revealed no evidence of tuberculosis, scrotum surgery, scrotal trauma,or previous urinary tract infection. On physical examination, multiple lumps were found arising from the scrotal skin, the largest one measuring $1.5 \mathrm{~cm}$. 
The lumps were freely movable non-tender and elastic. There were no palpable groin lymph nodes. The overlying skin showed no abnormality (fig.1.a). Ultrasonography of the local part indicated testes of normal consistency without free fluid in the tunica of scrotum. The laboratory workup revealed that the blood cell, blood electrolyte and thyroid hormone were within the normal limits.A complete surgical excision of the lumps,including the elliptical covering skin , was performed,and we reconstructed the scrotum wall in situ without skin graft,The lumps were located within the subcutaneous layer and sharply demarcated from surrounding structures(fig.1.b). On gross inspection,they were filled compactly with a soft, yellowish-white pastelike material. The cystic wall showed no solid portion without evidence of secondary foreign body-type granulomatous reaction or abscess. On histological examination of the excised specimen showed a cystic structure which composed of thin layers of fibrous connective tissue. The cyst-wall is lined with layered squamous epithelium.The cyst-wall cells are arranged regularly, without atypia,and the cystic cavity was filled with plenty of homogeneous red-dyed structureless keratin materials(fig.2).There were no teratomatous components or adnexal structures such as hair follicles, sebaceous glands, or sweat glands within the cystic lumen. The patient recovered well without any complications.

\section{Discussion}

Epidermoid cysts are very common tumors in the subcutaneous tissues and have been observed in several organs,especially in the skin of the scalp, ear, face, and back. Epidermal cysts have been reported in the perineum, penis, testis, and scrotum. Extratesticular scrotal epidermoid cysts are relatively rare in contrast to intratesticular ones. The precisely histogenesis of the epidermoid cyst is still unknown. However, the histogenesis of the extratesticular scrotal epidermoid cyst was considered for an abnormal closure or associated degenerative process of the median raphe and urethral groove[4, 5].They are generally devoid of malignant potential, but malignant transformations of basal cell carcinoma or squamous cell carcinoma from epidermal cysts have been reported[6, 7] .

Multiple epidermal cysts over the scrotum is a rare disease,and these lesions use to be ignored by the patient because of its painless. Some patients want a treatment just because of its unaesthetic.Although a few cases was reported of epidermal cysts infected.But the cyst being in proximity with potentially infective area may catch infection from it. If the cyst becomes infected, it will becomes painful and may burst to discharge pus. Single infected cyst can be drained without complications. It may spread in surrounding cysts and finally scrotal wall without a timely treatment.Once the scrotal skin is infected, the infected part has to be widely excised to avoid necrotizing fascitis of the scrotum and septicemia[8].

Scrotal ultrasonography is usually the first and the most important imaging modality to investigate scrotal and inguinal pathologic conditions, which can reliably differentiate extratesticular from intratesticular ones, as well as cystic from solid ones, with very high accuracy. The sonographic appearance of an epidermal cyst varies from an anechoic lesion to a hyperechoic, solid appearing mass,depending on its content. Although there are no specific pathognomonic findings to diagnose the epidermoid cysts accurately, on the color flow Doppler sonography,they are often appeared with 
well-demarcated hypoechoic masses with multiple scattered reflectors from the keratinous debris and posterior sound enhancement without internal vascular signals [8].

On MRI, epidermal cysts are described as high-intensity, well-defined solid masses surrounded by a lowsignal capsule on T2-weighted imaging[9]. On histological,the cyst-wall is lined by stratified squamous epithelium filled with laminated keratin, cholesterol crystals, and debris $[10,11]$. The diagnostic process of epidermoid cysts of the scrotum depends on the clinical history, radiological dates,clinical appearance,physical features and histopathologic analysis. There are few reports of malignant transformation of epidermoid cysts. Since epidermoid cysts of the scrotum are not malignant, complete surgical excision of the cyst including the elliptical covering skin with follow up is sufficient as the treatment of an epidermal cysts. If the epidermal cysts is gather together in one area over the scrotum skin, a total excision of the lesion scrotum wall should be taken,and the wound could be covered by the skin graft when it is difficult to suture the skin directly.

\section{Conclusions}

In summary,multiple epidermal cysts over the scrotum are rare, and correct diagnosis depends on the clinical history, radiological dates,clinical appearance,physical features and histopathologic analysis. The accumulation of further cases is needed to help understand the precisely histogenesis, diagnosis, and treatment of this disease.

\section{Abbreviations}

MRI

Magnetic resonance imaging.

\section{Declarations}

\section{Acknowledgements}

We thank the patient for allowing us to publish his case.

\section{Availability of the data and materials}

All the data are available in the patient's medical record.

\section{Authors' contributions}


SCW and GYLwas responsible for this patient's operation, conducted a literature search and drafted with the manuscript. HX was involved in the pathological diagnosis of the mass. WBN,XZ and FL revised the manuscript and wrote the final version of the manuscript. All authors have read and approved the final manuscript.

\section{Funding}

Not applicable.

\section{Declarations}

Ethics approval and consent to participate

Not applicable.

\section{Consent for publication}

Written informed consent was obtained from the patient for the publication of this case report and the accompanying images.

\section{Competing interests}

The authors declare that they have no conflict of interest.

\section{Author details}

1*\&1\&1^ Department of Urologic,Shenzhen Samii International Medical Center(The Fourth People's Hospital of Shenzhen), No.1 Jin Niu west Street,Pingshan District,Shenzhen 518118, Guangdong Province, China.

\section{References}

[1] Yang Wei Tse,Whitman Gary J,Tse Gary M K. Extratesticular epidermal cyst of the scrotum.[J]. AJR Am J Roentgenol,2004,183(4):1084.

[2] Bhatt V, Evans M, Malins TJ. Squamous cell carcinoma arising in the lining of 
an epidermal cyst within the sublingual gland e a case report[J]. Br J Oral Maxillofac Surg,2008,46:683685.

[3] Huang CC, Ko SF, Huang HY,et al. Epidermal cysts in the superficial soft tissue sonographic features with an emphasis on the pseudotestis pattern[J]. J Ultrasound Med ,2011,30:11-17.

[4] Katergiannakis V, Lagoudianakis EE, Markogiannakis $\mathrm{H}$,et al. Huge epidermoid cyst of the spermatic cord in an adult patient[J]. Int J Urol,2006,13:95-97.

[5] Picanco-Neto JM, Lipay MA, D'Avila CL, et al. Intrascrotal epidermoid cyst with extension to the rectum wall: A case report[J].J Pediatr Surg,1997,32:766-767.

[6] Prasad KK, Manjunath RD. Multiple epidermal cysts of scrotum[J]. Indian J Med Res,2014,140:318.

[7] Miller JM.Squamous cell carcinoma arising in an epidermal cyst[J]. Arch Dermatol, 1981,117:683.

[8] Kavita Mardi. Multiple scrotal epidermal cysts: A rare case report[J]. Journal of Clinical Sciences,2014,11(1):20-21.

[9] Cho JH, Chang JC, Park BH, et al.Sonographic and MR imaging findings of testicular epidermoid cysts[J]. AJR Am J Roentgenol,2002,178:743-748.

[10] Correa AF, Gayed BA, Tublin ME, et al.Epidermal inclusion cyst presenting as a palpable scrotal mass[J]. Case Rep Urol, 2012,2012:498-501.

[11] Shah KH, Maxted WC, Chun B.Epidermoid cysts of the testis: a report of three cases and an analysis of 141 cases from the world literature[J]. Cancer,1981,47:577-582.

\section{Figures}



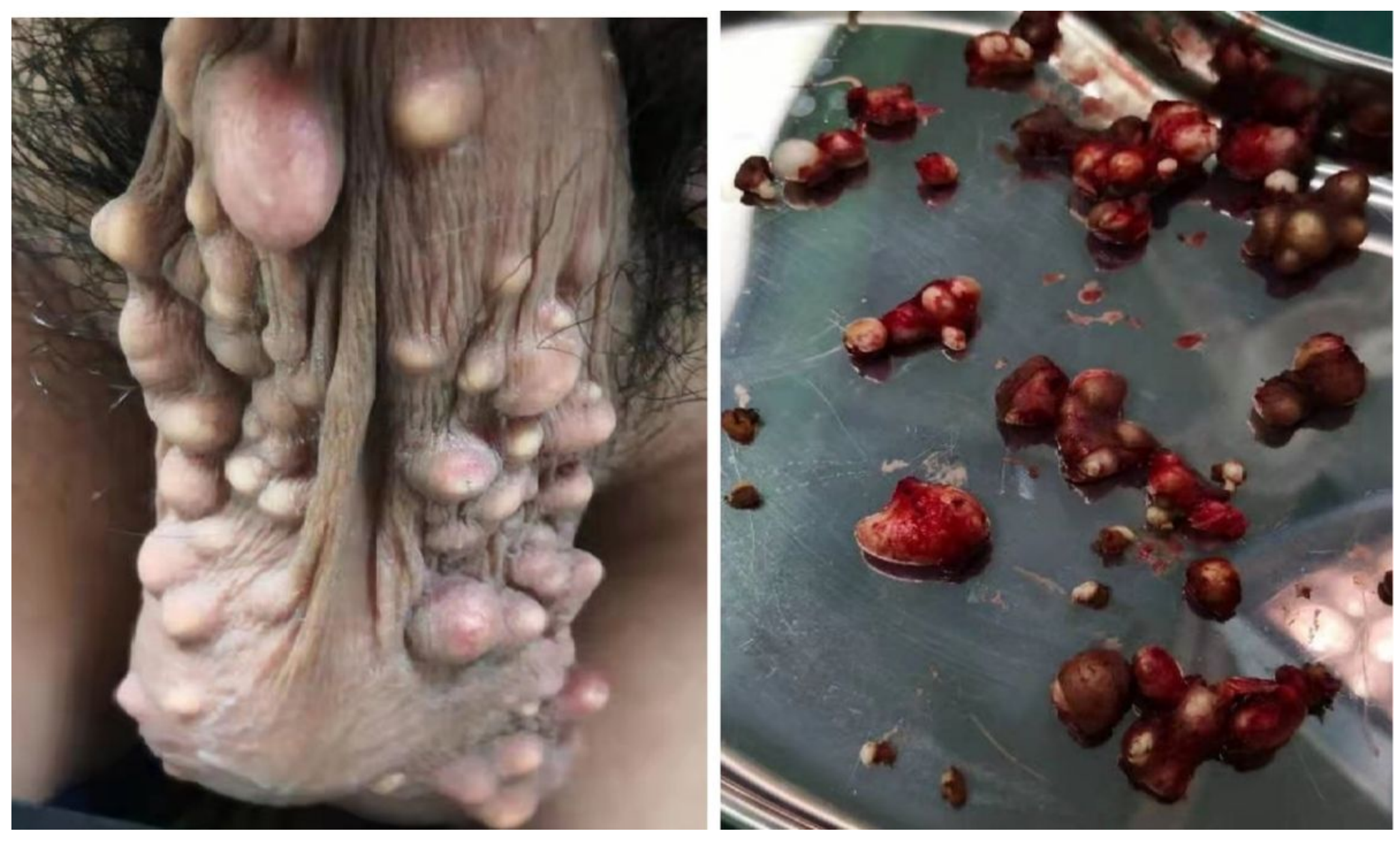

\section{Figure 1}

Photograph of the scrotal wall before surgical excision shows multiple nodule (a), and after surgical excision (b). 

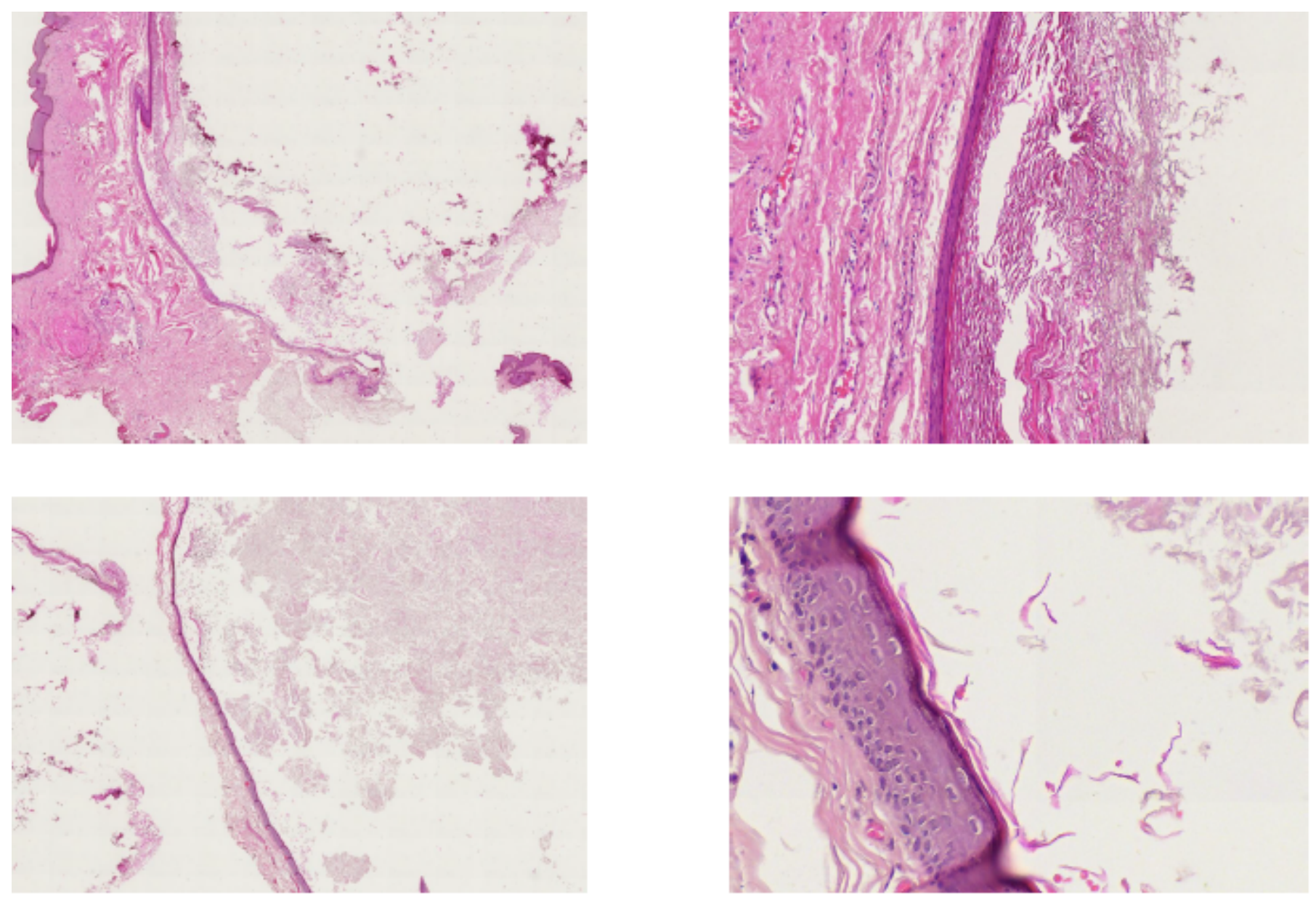

Figure 2

Epidermoid cyst composed of thin layers of fibrous connective tissue.The cyst-wall is lined with layered squamous epithelium. The cyst-wall cells are arranged regularly, without atypia,and the cystic cavity was filled with plenty of homogeneous red-dyed structureless keratin materials (hematoxylin and eosin, 40x). 